\title{
Anatomic Variations of Pancreaticobiliary Union
}

\author{
Fadil Sherifi ${ }^{1,2^{*}}$, Sadi Bexheti ${ }^{1}$, Zaim Gashi $^{2}$, Ismet Bajraktari ${ }^{3}$, Jeton Shatri ${ }^{1,4}$, Ali Lahu $^{5}$ \\ ${ }^{1}$ Institute of Anatomy, Medical Faculty, University of Prishtina, Prishtina, Kosovo; ${ }^{2}$ Clinic of Gastroenterology with \\ Hepatology, University Clinical Centre of Kosovo, Prishtina, Kosovo; ${ }^{3}$ Medical University "Resonance", Prishtina, Kosovo; \\ ${ }^{4}$ Clinic of Radiology, University Clinical Centre of Kosovo, Prishtina, Kosovo; ${ }^{5}$ University "Fama", Prishtina, Kosovo
}

\begin{abstract}
Citation: Sherifi F, Bexheti S, Gashi Z, Bajraktari I, Shatri J, Lahu A. Anatomic Variations of 2018 . https://doi.org/10.3889/oamims.2018.196

Keywords: Diethyntosanine, Hepatocelldar carcinom; Renin-angiotensin system; Survival analysis

*Correspondence: Fadil Sherifi. Institute of Anatomy, Medical Faculty, University of Prishtina, Prishtina, Kosovo; Clinic of Gastroenterology with Hepatology, University drfsh038@gmail.com

Received: 09-Feb-2018; Revised: 21-May-2018; Accepted: 22-May-2018; Online first: 08-Jun-2018

Copyright: ๑) 2018 Fadil Sherifi, Sadi Bexheti, Zaim Gashi, Ismet Bajraktari, Jeton Shatri, Ali Lahu. This is an open-access article distributed under the terms of the International License (CC BY-NC 4.0)

Funding: This research did not receive any financial support

Competing Interests: The authors have declared that no competing interests exis
\end{abstract}

\begin{abstract}
AIM: This study was designated to evaluate the frequency of anatomic variations of the pancreaticobiliary union.

MATERIALS AND METHODS: Our research was observational, comparative and analytical. The investigation was conducted from January 2016-May 2017. This study included 63 patients from Clinic of Gastroenterology and Hepatology - Prishtina, assessed pancreaticobiliary union with Magnetic Resonance cholangiopancreatography.

RESULTS: Union of the common bile duct and the major pancreas was biliary-pancreatic type The angle between common bile duct and the major pancreas duct had different sizes average $35.6^{\circ}$. We did not distinguish significant statistical significance in the size of the pancreaticobiliary angle. In men, the union angle was from the average $36.9^{\circ}$, while in females was average $34.3^{\circ}$. No correlation between the age and size of the angle between common bile duct and the major pancreas duct.

CONCLUSIONS: The union of the common bile duct and the major pancreas duct was in most cases B-P Type. The common channel and angle between common bile duct and the major pancreas duct were normal in most
\end{abstract} cases.

\section{Introduction}

Normally, the major pancreatic duct and the common bile duct open into the second part of the duodenum alone or after joining as a common channel. The length of the common channel ranges from 1-12 mm normally, with a mean of about $4-5 \mathrm{~mm}$ [1].

The junction of the common bile duct and pancreatic duct is crucial for sphincteric control of bile and pancreatic juice drainage, with bidirectional regurgitation occurring if the union is above Oddi's sphincter. An abnormal pancreaticobiliary junction is a junction of the common bile duct and the main pancreatic duct outside the wall of the duodenum that forms a long common channel $(<8 \mathrm{~mm})$ [2].

According to the type of biliary duct and main pancreatic duct joining the duodenal wall, the joining was classified into three categories: $V$ type, B-P type and $\mathrm{P}-\mathrm{B}$ type. The $\mathrm{V}$ type is the pancreatic duct and biliary duct joining the duodenal wall without a common channel; the B-P type is the biliary duct draining into the pancreatic duct and forming a common channel, and the P-B type is the pancreatic duct draining into the biliary duct and forming a common channel. Studies have revealed that the P-B type was equal to an acute angle and the B-P type was equal to a right angle [3] [4]. 
In 2015, the Committee on Diagnostic Criteria of the Japanese Study Group on Pancreaticobiliary Maljunction (PBM) proposed a classification of PBM into four types: (A) stenotic type, (B) non-stenotic type, (C) dilated channel type, and (D) complex type [5].

According to Kimura, the mode of the abnormal pancreaticobiliary junction can be classified into 2 types: type I in which the main pancreatic duct enters the common bile duct and type II in which the common bile duct enters the pancreatic duct [6].

The frequency of anomalous arrangement of the pancreaticobiliary duct (AUPBD) varies from 1.5$3.2 \%[7]$.

The anatomy of the distal ends of the common bile duct and the main pancreatic duct has received attention because of its importance in pancreaticobiliary diseases. The two ducts open in the duodenum either separately or via a common channel [8].

The junction of the common bile duct and pancreatic duct is crucial for sphincteric control of bile and pancreatic juice drainage, with bidirectional regurgitation occurring if the union is above Oddi's sphincter. An abnormal pancreaticobiliary junction is a junction of the common bile duct and the main pancreatic duct outside the wall of the duodenum that forms a long common channel $(<8 \mathrm{~mm})$ [2].

Magnetic resonance cholangiopancreatography (MRCP), which is widely used in the clinic, is a noninvasive and multidirectional imaging technology that can also clearly display the anatomical structure of the pancreaticobiliary duct system [9].

This study aimed to evaluate the frequency of anatomic variations of pancreaticobiliary union presented by the magnetic resonance cholangiopancreatography (MRCP). The most specific purpose was to assess the variations by tips, angle and relations with gender and age groups.

\section{Material and Methods}

Our research was observational, comparative and analytical. Regarding time, it was retrospective research. The investigation was conducted in January 2016-May 2017. This study included hospitalised and outpatient patients in Clinic of Gastroenterology and Hepatology, University Clinical Center of Kosovo. The examinations were carried out using the Siemens Type of MRCP in patients at Private Hospital "Aloka" in Prishtina and Clinic of Radiology, University Clinical Center of Kosovo. In this study, 63 (32 males and 31 females) were included. Patients were assessed pancreaticobiliary Union with MRCP (Magnetic
Resonance cholangiopancreatography). The data was presented with tables.

Mann-Whitney, One Way ANOVA and Kruskal-Wallis tests were used.

\section{Results}

The union of the common bile duct and the major pancreas duct in $31.7 \%$ of the cases was B-P Type (biliary pancreatic). The most common women were P-B Type with $12.9 \%$ of cases compared with $3.1 \%$ males (Table 1 ).

Table 1: The Union of the common bile duct and the major pancreas duct by sex

\begin{tabular}{|c|c|c|c|c|c|c|}
\hline \multirow[b]{2}{*}{ Types of PB Union } & \multicolumn{2}{|c|}{$\mathrm{M}$} & \multicolumn{2}{|c|}{$\mathrm{F}$} & \multicolumn{2}{|c|}{ Total } \\
\hline & $\mathrm{N}$ & $\%$ & $\mathrm{~N}$ & $\%$ & $\mathrm{~N}$ & $\%$ \\
\hline Separated or "duodenal" Type & 10 & 31.3 & 8 & 25.8 & 18 & 28.6 \\
\hline B-P (biliarypancreatic) Type & 11 & 34.4 & 9 & 29.0 & 20 & 31.7 \\
\hline P-B (pancreaticobiliary) Type & 1 & 3.1 & 4 & 12.9 & 5 & 7.9 \\
\hline Pathology that deform PB Union & 9 & 28.1 & 10 & 32.3 & 19 & 30.2 \\
\hline Artefacts & 1 & 3.1 & - & - & 1 & 1.6 \\
\hline Total & 32 & 100.0 & 31 & 100.0 & 63 & 100.0 \\
\hline
\end{tabular}

At age $20-29$ in $100.0 \%$ of cases, union common bile duct and the major pancreas was "duodenal type" (separated), while age over 70 years in $50.0 \%$ of cases was B-P type. The angle between common bile duct and the major pancreas duct had different sizes from $4^{\circ}$ to $90^{\circ}$ average $35.6^{\circ}$ (SD \pm $\left.21.1^{\circ}\right)$.

Table 2: The union common bile duct and the major pancreas duct by age

\begin{tabular}{|c|c|c|c|c|c|c|c|c|c|c|c|c|c|c|c|c|}
\hline \multirow{3}{*}{ Types of PB Union } & \multicolumn{14}{|c|}{ Age by years } & \multirow{2}{*}{\multicolumn{2}{|c|}{ Total }} \\
\hline & \multicolumn{2}{|c|}{$20-29$} & \multicolumn{3}{|c|}{$30-39$} & & -49 & \multicolumn{2}{|c|}{ 50-59 } & \multicolumn{2}{|c|}{$60-69$} & & \multicolumn{2}{|c|}{$70+$} & & \\
\hline & $\mathrm{N}$ & $\%$ & $\Lambda$ & & $\%$ & $\mathrm{~N}$ & $\%$ & $\mathrm{~N}$ & $\%$ & $\mathrm{~N}$ & $\%$ & & $\mathrm{~N}$ & $\%$ & $\mathrm{~N}$ & $\%$ \\
\hline $\begin{array}{l}\text { Separated (V) or } \\
\text { "duodenal" Type } \\
\text { B-P }\end{array}$ & 4 & 100. & 1 & & 12.5 & 3 & 27.3 & 4 & 26.7 & 3 & 33. & & 3 & 18.8 & 18 & 28.6 \\
\hline $\begin{array}{l}\text { (biliarypancreatic) } \\
\text { Type }\end{array}$ & - & - & & & 25.0 & 3 & 27.3 & 5 & 33.3 & 2 & 22. & & 8 & 50.0 & 20 & 31.7 \\
\hline & & & & & & & & & & & & & & & & \\
\hline $\begin{array}{l}\text { Type } \\
\text { Pathology that }\end{array}$ & - & - & & & - & 2 & 18.2 & 1 & 6.7 & 1 & 11. & & 1 & 6.3 & 5 & 7.9 \\
\hline deform PB Union & - & - & 5 & & 62.5 & 2 & 18.2 & 5 & 33.3 & 3 & 33. & & 4 & 25.0 & 19 & 30.2 \\
\hline Artefacts & - & & & & $\therefore$ & 1 & 9.1 & - & & & & & if & - & 1 & 1.6 \\
\hline 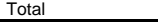 & 4 & 100. & 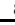 & & 00.0 & 11 & 100.0 & 15 & 100.0 & 9 & 100 & & 16 & 100.0 & 63 & 100.0 \\
\hline
\end{tabular}

With the Mann-Whitney test, we did not distinguish significant statistical significance in the size of the PB angle. Based in gender $(P=0.633)$ in men the PB was from $5^{\circ}$ to $61^{\circ}$ with the average $36.9^{\circ}$, while the females from $4^{\circ}$ to $90^{\circ}$, with the average $34.3^{\circ}$ (Table 3 ).

Table 3: The angle between common bile duct and the major pancreas duct by sex

\begin{tabular}{|c|c|c|c|}
\hline \multirow[b]{2}{*}{ Size of PB angle } & \multicolumn{2}{|c|}{ Sex } & \multirow[b]{2}{*}{ Total } \\
\hline & $\mathrm{M}$ & $\mathrm{F}$ & \\
\hline $\mathrm{N}$ & 32 & 31 & 63 \\
\hline Mean value & $36.9^{\circ}$ & $34.3^{\circ}$ & $35.6^{\circ}$ \\
\hline SD & $19.1^{\circ}$ & $23.8^{\circ}$ & $21.1^{\circ}$ \\
\hline Min & $5^{\circ}$ & $4^{\circ}$ & $4^{\circ}$ \\
\hline Max & \multirow{2}{*}{\multicolumn{2}{|c|}{$P=0.633$}} & $90^{\circ}$ \\
\hline Mann-Whitney test & & & \\
\hline
\end{tabular}


a)

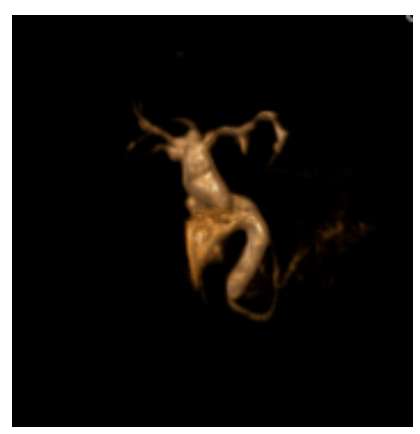

b)

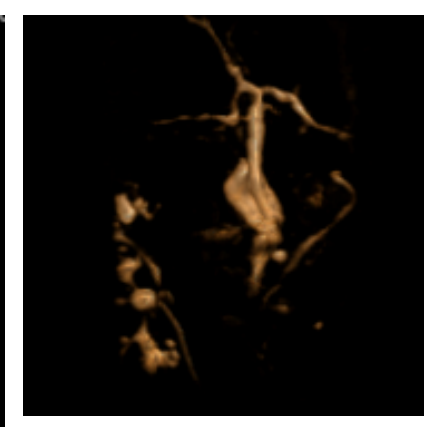

c)

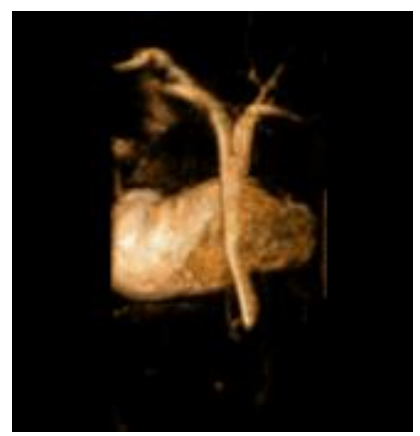

d)

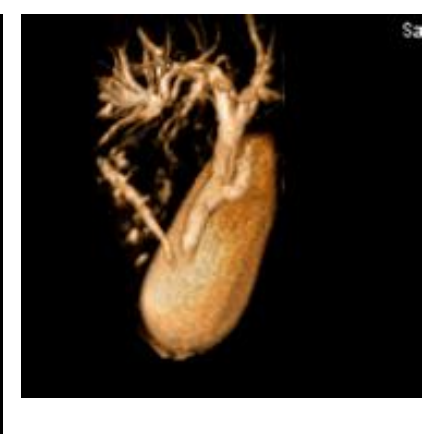

e)

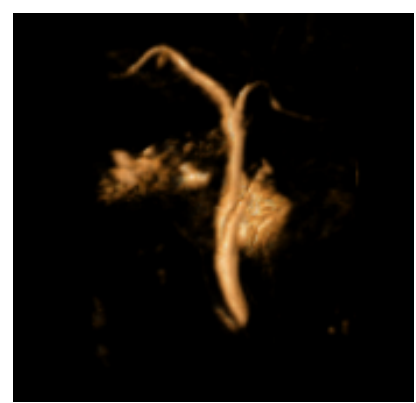

f)

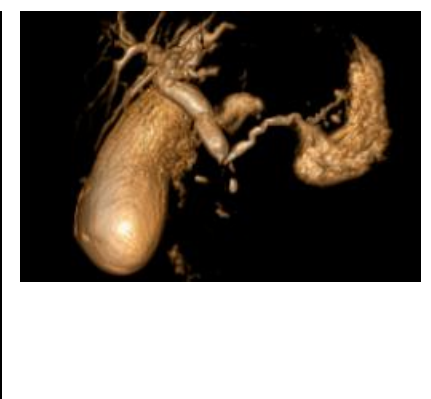

Figure 1: $P B$ images of MRCP. a) Common bile duct joined main pancreatic duct (B-P Type); b) Common bile duct and major pancreatic duct are separated ( $V$ Type), narrow-angle between ducts is presented; c) Major pancreatic duct joined common bile duct ( $P$-B Type); d) Common bile duct and major pancreatic duct are separated ( $V$ Type); e) Image shows narrow-angle between ducts; $B-P$ Type is presented; f) Image presented right angle between ducts duct ( $V$ type)

We did not find any correlation between the age and size of the angle between common bile duct and the major pancreas duct $(P=0.782)$, (Table 4).

Table 4: The angle between common bile duct and the major pancreas duct by age

\begin{tabular}{lccccccc}
\hline & \multicolumn{7}{c}{ Age by years } \\
\cline { 2 - 6 } Size of PB angle & $20-29$ & $30-39$ & $40-49$ & $50-59$ & $60-69$ & $70+$ & Total \\
\hline $\mathrm{N}$ & 4 & 8 & 11 & 15 & 9 & 16 & 63 \\
Mean value & $32.0^{\circ}$ & $61.5^{\circ}$ & $31.0^{\circ}$ & $43.4^{\circ}$ & $4.5^{\circ}$ & $32.2^{\circ}$ & $35.6^{\circ}$ \\
$\mathrm{SD}$ & $3.5^{\circ}$ & $2.3^{\circ}$ & $15.6^{\circ}$ & $15.8^{\circ}$ & $0.7^{\circ}$ & $14.9^{\circ}$ & $21.1^{\circ}$ \\
Min. & $29.0^{\circ}$ & $48.0^{\circ}$ & $15.0^{\circ}$ & $21.0^{\circ}$ & $4.0^{\circ}$ & $11.0^{\circ}$ & $4.0^{\circ}$ \\
Max. & $35.0^{\circ}$ & $63.0^{\circ}$ & $52.0^{\circ}$ & $61.0^{\circ}$ & $5.0^{\circ}$ & $58.0^{\circ}$ & $63.0^{\circ}$ \\
Kruskal Wallis Test & \multicolumn{7}{c}{$\mathrm{K}=1.32, \mathrm{P}=0.782$} \\
\hline
\end{tabular}

The common channel in one case was 15 $\mathrm{mm}$. In other cases, it was 3-12 mm (Table 5).
Table 5: Size of common channel (between common bile duct and major pancreatic duct)

\begin{tabular}{lccc}
\hline Common channel (PB) & $\mathrm{M}$ & $\mathrm{F}$ & Total \\
\hline $\mathrm{N}$ & 12 & 13 & 25 \\
$\operatorname{Min}(\mathrm{mm})$ & 3 & 12 & 3 \\
$\operatorname{Max}(\mathrm{mm})$ & 10 & 15 & 15 \\
Mean value $(\mathrm{mm})$ & 4 & 5 & 4.5 \\
\hline
\end{tabular}

\section{Discussion}

The union of the common bile duct and the major pancreas duct in $31.7 \%$ of the cases was B-P Type (biliary pancreatic). The most common women were P-B Type with $12.9 \%$ of cases compared with $3.1 \%$ males.

At age $20-29$ in $100.0 \%$ of cases, the union common bile duct and the major pancreas duct was "duodenal" or separated type, while the age over 70 years in $50.0 \%$ of cases was type B-P. The common channel in one case was $15 \mathrm{~mm}$. In other cases, it was 3-12 $\mathrm{mm}$. On MRCP, the length of the common channel was calculated to be $15 \mathrm{~mm}$ or longer in nine $(82 \%)$ of 11 patients with anomalous PBJ. In patients with normal PBJ, MRCP identified PBJ with the channel measuring $0 \mathrm{~mm}$ in length [10]. The types of the anomalous pancreaticobiliary ductal union as determined on MR cholangiopancreatography (type A, $\mathrm{n}=2$; type $\mathrm{B}, \mathrm{n}=7$; type $\mathrm{C}, \mathrm{n}=3$ ) were concordant with those of intraoperative cholangiography in 11 of 12 patients. In five of eight patients with choledochal cyst (type la, $n=1$; type IVa, $n=5$; type IVb, $n=2$ ) in whom MR cholangiopancreatography could not depict anomalous pancreaticobiliary ductal union, anomalous pancreaticobiliary ductal union was documented on intraoperative cholangiography that was performed after choledochal cyst resection [11].

The frequency of AUPBD varies from 1.5$3.2 \%$. Its diagnosis needs a high index of suspicion and carefully performed investigations. Komi et al., in their new classification described 51 cases of AUPBD. Of these, 35.5\% were Type I, 21.6\% were Type II, and $43.1 \%$ were type III. Type III was sub-divided into three types ( $A$, $B$ and $C)$. Type $C$ is further divided into three sub-types (1, 2 and 3) [7].

The angle between common bile duct and the major pancreas duct had different sizes from $4^{\circ}$ to $90^{\circ}$ average $35.6^{\circ}\left(S D \pm 21.1^{\circ}\right)$. With the Mann-Whitney test, we did not distinguish significant statistical significance in the size of the $\mathrm{PB}$ angle. Based in gender $(P=0.633)$ in men the $P B$ was from $5^{\circ}$ to $61^{\circ}$ with the average $36.9^{\circ}$, while the females from $4^{\circ}$ to $90^{\circ}$, with the average $34.3^{\circ}$.

The APJ (anomalous pancreaticobiliary junction) in group $A$ was smaller than in group $B$ $\left(51.45^{\circ} \pm 13.51^{\circ}\right.$ vs $\left.65.76^{\circ} \pm 15.61^{\circ}, P<0.05\right)$. According to the type of biliary duct and main pancreatic duct joining the duodenal wall, the 
prevalence of acute pancreatitis in the $V$ type and in the B-P type was higher than in the P-B type (12/17 vs. $10 / 29$, or $18 / 26$ vs. $10 / 29$, respectively, all $P$ $<0.05)$, whereas there was no significant difference in the prevalence of acute pancreatitis between the $\mathrm{V}$ type and B-P type $(P>0.05)$. The APJ were $59.32^{\circ} \pm$ $20.04^{\circ}, 60.22^{\circ} \pm 11.06^{\circ}, 57.13^{\circ} \pm 17.27^{\circ}$, respectively in $\mathrm{V}$ type, B-P type and P-B type joining of the main pancreatic duct $(P>0.05)$ [12]. We did not find any correlation between the age and size of the angle between common bile duct and the major pancreas duct $(P=0.782)$.

Misra and his colleagues reported that a common channel with a mean length of $4.7 \pm 2.5 \mathrm{~mm}$ (range, 1.6 to $18.4 \mathrm{~mm}$ ) was present in $64(63 \%)$ of 102 normal endoscopic retrograde cholangiopancreatography films [2]. The reported frequency of abnormal pancreaticobiliary junction ranged from $1.5 \%$ to $3.2 \%$ in different ethnic populations [13].

Wang et al. found an abnormal pancreaticobiliary junction in 59 (3.4\%) of 1752 subjects undergoing endoscopic retrograde cholangiopancreatography [14]. In 1973, Babbitt et al. proposed abnormal pancreaticobiliary junction as the aetiology of choledochal cyst [15].

Kimura et al., studied 65 patients with the abnormal pancreaticobiliary junction and found that 49 (75.4\%) had choledochal cyst alone, $11(16.9 \%)$ had gallbladder cancer alone, and $5(7.7 \%)$ had both choledochal cyst and gallbladder cancer [6].

These findings were confirmed by Wang et al., who found that $62.5 \%$ (5 of 8 ) of patients with gallbladder cancer and $33.3 \%$ (9 of 27) of patients with common bile duct cancer had an abnormal pancreaticobiliary junction [14].

AUPBD is a well described though uncommon, and often unrecognised, the cause of acute pancreatitis, especially in young patients. It has also been associated with gallbladder carcinoma. In one study, anomalous ductal union occurred in $16.7 \%$ of the patients with gallbladder carcinoma in comparison with an incidence of $2.8 \%$ among 641 consecutive patients with various hepatobiliary and pancreatic diseases. Gallbladder carcinoma occurred in $24.6 \%$ of the 65 cases of the anomalous ductal union in comparison with a $1.9 \%$ incidence of this cancer among 635 consecutive patients similarly studied and found to have a normal ductal union [2].

In conclusion, the union of the common bile duct and the major pancreas duct was B-P Type. The common channel was normal in most cases. The angle between common bile duct and the major pancreas duct had different size. We did not distinguish significant statistical significance in the size of the $\mathrm{PB}$ angle. $\mathrm{PB}$ angle on average in men was $36.9^{\circ}$, while in females $34.3^{\circ}$. No correlation between the age and size of the angle between common bile duct and the major pancreas duct.

\section{References}

1. Misra SP, Dwivedi M. Pancreaticobiliary ductal union. Gut. 1990; 31(10):1144-1149. https://doi.org/10.1136/gut.31.10.1144

2. Misra SP, Gulati P, Thorat VK, Vij JC, Anand BS.

Pancreaticobiliary ductal union in biliary diseases. An endoscopic retrograde cholangiopancreatographic study. Gastroenterology 1989; 96:907-912. https://doi.org/10.1016/S0016-5085(89)80095-2

3. Todani T, Watanabe Y, Fujii T, Uemura S. Anomalous arrangement of the pancreaticobiliary ductal system in patients with a choledochal cyst. Am J Surg. 1984; 147:672-6. https://doi.org/10.1016/0002-9610(84)90139-9

4. Yamauchi S, Koga A, Matsumoto S, Tanaka M, Nakayama F. Anomalous junction of pancreaticobiliary duct without congenital choledochal cyst: a possible risk factor for gallbladder cancer. Am J Gastroenterol. 1987; 82:20-4. PMid:3799576

5. Urushihara N, Hamada $Y$, Kamisawa T, Fujii H, Koshinaga T, Morotomi Y, Saito T, Itoi T, Kaneko K, Fukuzawa H, Ando H. Classification of pancreaticobiliary maljunction and clinical features in children. Journal of hepato-biliary-pancreatic sciences. 2017; 2017

6. Kimura K, Ohto M, Saisho H, Unozawa T, Tsuchiya Y, Morita M, Ebara M, Matsutani S, Okuda K. Association of gallbladder carcinoma and anomalous pancreaticobiliary ductal union. Gastroenterology. 1985; 89:1258-1265. https://doi.org/10.1016/0016-5085(85)90641-9

7. Komi N. New classification of anomalous arrangement of the pancreaticobiliary duct (APBD) in the choledochal cyst; a proposal of new Komi's classification of APBD. J Jpn Pancr Soc. 1991; 6: 234-43.

8. Hansson K. Experimental and clinical studies in aetiologic role of bile reflux in acute pancreatitis. Acta Chir Scand. 1967; 375(Suppl): 1-102.

9. Kamisawa T, Tu Y, Egawa N, Tsuruta K, Okamoto A, Kamata N. MRCP of congenital pancreaticobiliary malformation. Abdom Imaging. 2007; 32:129-33. https://doi.org/10.1007/s00261-0069005-3 PMid:16680507

10. Sugiyama M, Baba M, Atomi Y, Hanaoka H, Mizutani $Y$, Hachiya J. Diagnosis of anomalous pancreaticobiliary junction: value of magnetic resonance cholangiopancreatography. Surgery. 1998; 123(4):391-7. https://doi.org/10.1016/S0039-6060(98)70159$\underline{X}$

11. Kim MJ, Han SJ, Yoon CS, Kim JH, Oh JT, Chung KS, Yoo HS. Using MR cholangiopancreatography to reveal anomalous pancreaticobiliary ductal union in infants and children with choledochal cysts. American Journal of Roentgenology. 2002; 179(1):209-14. https://doi.org/10.2214/ajr.179.1.1790209 PMid:12076938

12. Liu N, Huang XH, Zhang XM, Dong GL, Jing ZL, Gao CL, Tang MY. The angle of pancreaticobiliary junction correlates with acute pancreatitis: a magnetic resonance cholangiopancreatography study. Quant Imaging Med Surg. 2015; 5(3):401-406

PMid:26029643 PMCid:PMC4426105

13. Kinoshita H, Nagata E, Hirohashi K, Sakai K, Kobayashi Y. Carcinoma of the gallbladder with an anomalous connection between the choledochus and the pancreatic duct. Report of 10 cases and review of the literature in Japan. Cancer. 1984; 54:762769. https://doi.org/10.1002/1097-0142(1984)54:4<762::AIDCNCR2820540429>3.0.CO;2-K

14. Wang HP, Wu MS, Lin CC, Chang LY, Kao AW, Wang HH, Lin JT. Pancreaticobiliary diseases associated with anomalous pancreaticobiliary ductal union. Gastrointest Endosc. 1998; 48:184-189. https://doi.org/10.1016/S0016-5107(98)70161-0 15. Babbitt DP, Starshak RJ, Clemett AR. Choledochal cyst: a concept of etiology. Am J Roentgenol Radium Ther Nucl Med. 1973; 119:57-62. https://doi.org/10.2214/air.119.1.57 PMid:4744730 